\title{
Review of monoclonal antibody therapies in asthma and allergic diseases - a new paradigm for precision medicine
}

\author{
Tak Lee, ${ }^{1}$ Parameswaran Nair, ${ }^{2}$ Christopher John Corrigan ${ }^{3}$
}

\begin{abstract}
Background: Elucidation of the critical immune pathways involved in allergic inflammation has identified, apart from IgE, therapeutic targets in the cytokine network suitable for intervention by biological therapies.

Objective: The drugs that target the cytokine networks pertinent to asthma and allergic diseases are reviewed and some illustrative case histories presented. The overview proposes a framework to use when deciding which monoclonal antibody ( $\mathrm{mAb}$ ) to select for treatment of severe asthma based on total IgE concentration, peripheral blood eosinophil count, induced sputum analysis and measurement of fractional exhaled nitric oxide (FENO).

Methods: Internet-based literature search including PubMed for studies on biological therapies targeting IgE and the cytokine network in allergic inflammation focusing on asthma with and without rhinosinusitis and nasal polyposis, eczema, urticaria and food allergies. Lists of pivotal trials published in the peer reviewed literature and pertaining to their own mAb products were also provided by GSK, AstraZeneca and Sanofi. Therapeutic agents licensed or in advanced stages of development (Phase $2 \mathrm{~b}$ and 3 ) were selected for discussion.
\end{abstract}

Results: The survey identifies a number of mAbs with substantial potential for the future targeted treatment of asthma with and without rhinosinusitis and nasal polyposis, eczema, urticaria and food allergies uncontrolled by existing therapies. A pragmatic framework is proposed for selecting the optimal $\mathrm{mAb}$ for initial use in individual patients with severe asthma.

Conclusions: Launch of these new biologicals may revolutionise the treatment of allergic diseases if employed in an endotype-specific fashion, heralding an unprecedented era of personalised medicine.

Key words: Asthma, Allergy, Cytokines, Biologicals, Precision Medicine

From:

${ }^{1}$ Allergy Centre, Hong Kong Sanatorium and Hospital Hong Kong

${ }^{2}$ Firestone Institute for Respiratory Health, McMaster University \& St Joseph's Healthcare, Hamilton, Ontario, Canada

${ }^{3}$ Faculty of Life Sciences \& Medicine, School of Immunology \&

Microbial Sciences, Asthma UK Centre in Allergic Mechanisms of

Asthma, King's College London, London, UK

\section{Introduction}

Specific humanised monoclonal antibodies (mAbs or 'biologicals') have been widely used worldwide for the treatment of cancers, rheumatological disorders, inflammatory bowel diseases and a wide spectrum of immunological disorders. The introduction of new mAbs and discovery of hitherto unknown indications for use of existing mAbs will likely revolutionise the treatment of allergic diseases in the context of targeted therapy and personalised healthcare.

\section{Corresponding author:}

Tak Lee

Allergy Centre, 9/F Li Shu Pui Block

HK Sanatorium and Hospital, 2 Village Road, Hong Kong

E-mail: takhong.lee@hksh.com

The article discusses mAbs that are already licensed and others that are in advanced development, which have substantial potential for the future treatment of five common diseases, namely asthma with and without rhinosinusitis with nasal polyposis, eczema, urticaria and food allergies, which are unresponsive to other therapies. (Figure 1) 


\begin{tabular}{|c|c|}
\hline $\begin{array}{c}\text { A Biological Treatments } \\
\text { For Disease }\end{array}$ & B Immune Targets \\
\hline $\begin{array}{c}\text { Asthma } \\
\text { omalizumab, mepolizumab, } \\
\text { benralizumab, dupilumab, } \\
\text { reslizumab, tezepelumab }\end{array}$ & $\begin{array}{c}\text { IgE } \\
\text { omalizumab, ligelizumab }\end{array}$ \\
\hline $\begin{array}{c}\text { Rhinosinusitis with nasal } \\
\text { polyposis } \\
\text { dupilumab }\end{array}$ & $\begin{array}{c}\text { IL-5 } \\
\text { mepolizumab, reslizumab }\end{array}$ \\
\hline $\begin{array}{c}\text { Eczema } \\
\text { dupilumab, lebrilizumab, } \\
\text { tralokinumab, fezakinumab }\end{array}$ & $\begin{array}{c}\text { IL-5 receptor } \\
\text { benralizumab }\end{array}$ \\
\hline $\begin{array}{c}\text { Urticaria } \\
\text { omalizumab, ligelizumab }\end{array}$ & $\begin{array}{c}\text { IL-4/13 receptor } \\
\text { dupilumab }\end{array}$ \\
\hline $\begin{array}{c}\text { Food allergies } \\
\text { omalizumab, etokimab }\end{array}$ & $\begin{array}{c}\text { IL-13 } \\
\text { tralokinumab, lebrikizumab }\end{array}$ \\
\hline & $\begin{array}{c}\text { TSLP } \\
\text { tezepelumab }\end{array}$ \\
\hline & $\begin{array}{c}\text { IL-22 } \\
\text { fezakinumab }\end{array}$ \\
\hline & IL-33 \\
& etokimab \\
\hline
\end{tabular}

Figure 1. Summary of biological treatments for asthma, rhinosinusitis with nasal polyposis, eczema, urticaria and food allergies (Panel A) and the immune targets for the monoclonal antibodies (Panel B).

\section{Cytokine regulation of allergic inflammation}

A simplified summary of cytokine regulation of allergic inflammation is shown in Figures 2 and 3. Historically it was hypothesised that Th2 $\mathrm{T}$ cell responses and the Th2 cytokine microenvironment were central to driving the allergic phenotype. ${ }^{1,2}$ (Figure 2) Dendritic cells were required for activation of naïve $\mathrm{T}$ cells and OX40L was an essential co-stimulatory mediator of Th2 responses. Prior to activation and maturation, DCs expressed very low levels of Major Histocompatibility Complex (MHC) and co-stimulatory molecules of their surfaces. However when allergen was internalized and processed by DCs the expression of MHC class II molecules, Cluster of Differentiation (CD)40 and B7 (required for T cell activation) were upregulated. The primed DCs migrated to regional draining lymph nodes to activate naïve $\mathrm{T}$ cells through an interaction with the counter co-stimulatory molecules on $\mathrm{T}$ cells that included CD28 and CD40 ligand (CD40L).

Activation of naïve $\mathrm{T}$ cells in an atopic individual was driven down the pathogenic Th2, as distinct from the Th1 pathway. Activated Th2 cells released Interleukin (IL)- 4 and IL-13 in the presence of CD40L to promote IgE synthesis by primed B cells. The allergen-specific IgE bound to mast cells via the high affinity IgE receptor (FceRI), which in turn released their inflammatory mediators upon cross linking of membrane-bound IgE by allergen. Th2 cells also produced IL- 5 which increased eosinophil differentiation, growth and maturation in the bone marrow and primed them for activation. Th2 derived IL-4, IL-9 and IL-13 stimulated epithelial cells and smooth muscle to undergo structural remodelling and mucus hypersecretion as well as to contribute to the production of eosinophilotactic chemokines, such as CCL11 (eotaxin), thereby amplifying the inflammatory reaction.

However, more recently, a number of mechanisms have been discovered which have necessitated a reconsideration of the classical Th2 hypothesis. For instance, it has become abundantly clear that many innate immune cells, especially innate, type 2 lymphocytes (ILC2) also produce Th2-type cytokines and that these can promote differentiation of Th2-like $\mathrm{T}$ cells by inducing local OX40L expression on DCs and local class switching of B cells to IgE synthesis. (Figure 3) These ILCs are activated by the alarmins (alarm signalling molecules), ${ }^{3}$ namely Thymic Stromal Lymphopoietin (TSLP), ${ }_{4}^{4}$ IL- $33^{5}$ and IL-25. ${ }^{6,7}$ Alarmins are expressed in epithelial cells, endothelial cells and lymphoid organs and released in response to stimuli that include pollutants, viruses and proteins with protease activities acting on protease-activated receptors (PARs), such as house dust mites. Alarmins not only cause Th2 T cell differentiation but also elicit structural remodelling. (Figure 3) TSLP activates immature DCs by binding to the TSLP receptor (TSLPR) and the alpha chain of IL-7 receptor (IL-7R). IL-33 acts through the suppression of tumorigenicity 2 (ST2) receptor on ILC2 to release IL-5 and IL-13. ILC2 cells, in contrast to Th2 cells, are resistant to inhibition to glucocorticoids and in the relatively prednisolone-resistant patients, it is likely that ILC2 cells are the predominant source of IL-5 and IL-13 that contribute to eosinophil recruitment. ${ }^{8,9}$ IL-25 (IL-17E) supports the Th2 immune response and induces the production of Th2 cytokines. Against the background of this cytokine network, new immune targets for the development of mAbs can be identified. (Figure 1)

\section{ANTI IgE}

Omalizumab (Xolair) binds to the $3^{\text {rd }}$ constant region of the IgE molecule and prevents free IgE from interacting with the high and low-affinity IgE receptors (FceRI and FceRII). The drug is effective regardless of allergen specificity. It rapidly reduces free but not total serum IgE concentrations by over $95 \%$ and also reduces IgE receptor density on mast cells or basophils. In addition it may restore impaired, innate anti -viral immunity through enhanced IFN-alpha responses in plasmacytoid DCs (pDCs) by decreasing allergen bound IgE on pDCs. ${ }^{10}$

Dependent on the patient's weight $(40-120 \mathrm{~kg})$ and total serum IgE concentration (30-1500 kU/L) omalizumab at a dose between $150-375 \mathrm{mg}$ is administered subcutaneously every 2 or 4 weeks, with a maximum dosage of 750 mg every 4 weeks. The drug is positioned at step 5 of the Global Initiative For Asthma (GINA) guidelines. ${ }^{11}$

A summary analysis of 12 clinical trials of 6427 patients showed that omalizumab therapy reduces the risk of asthma exacerbations and the need for glucocorticoid therapy. ${ }^{12}$ Omalizumab also reduced airway mucosal IgE+ cells and improved non-atopic asthma. ${ }^{13}$ Adverse events (AEs) include injection site reactions (10\%), headache 27\%), back pain (13\%), pruritus (1-10\%), nasopharyngitis (1-10\%), nausea and abdominal pain (1-10\%). However, in patients who have severe asthma requiring daily prednisolone, the effectiveness of omalizumab is still unclear. ${ }^{14}$ Omalizumab did not suppress sputum eosinophilia in these patients suggesting that atopy 


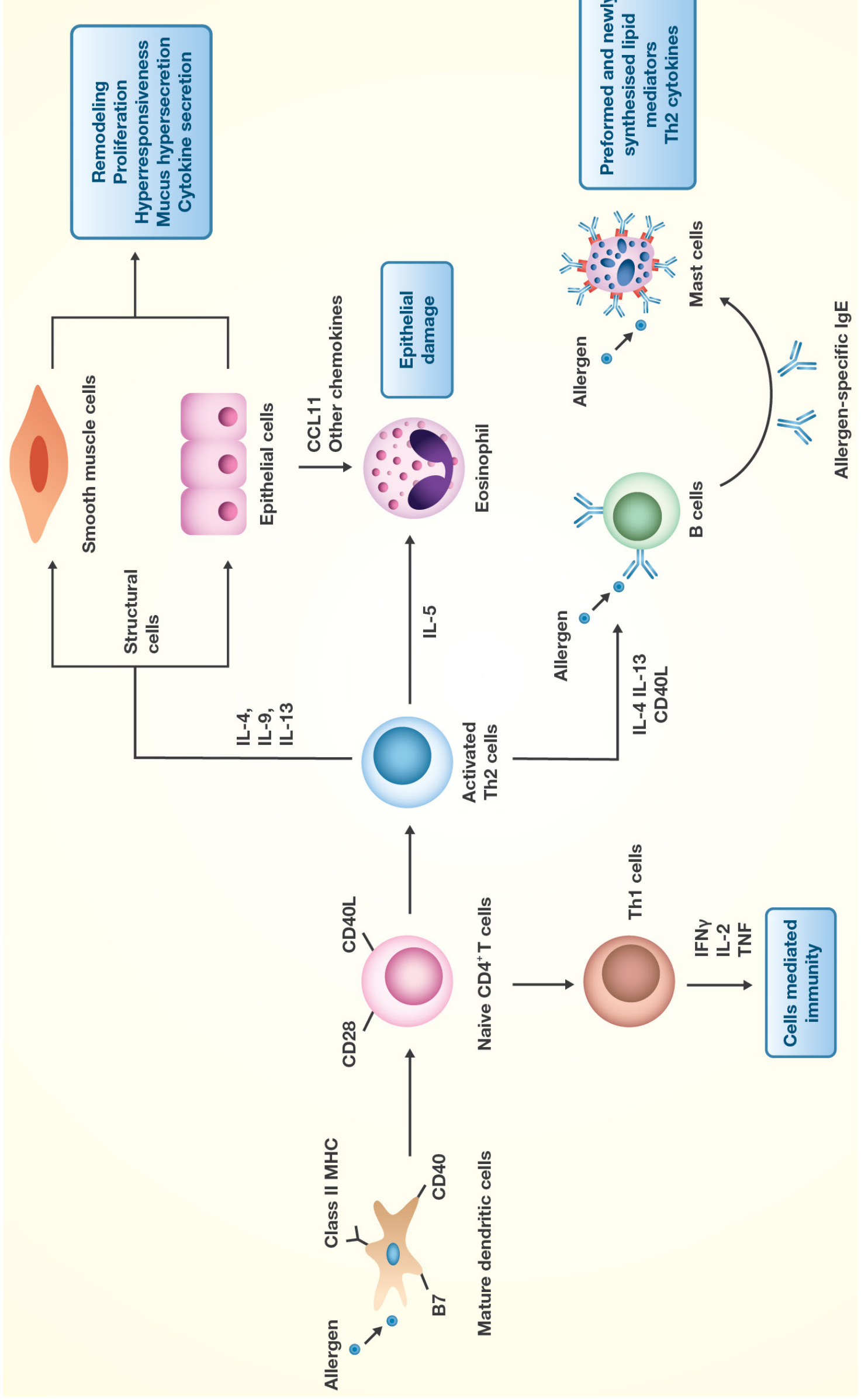




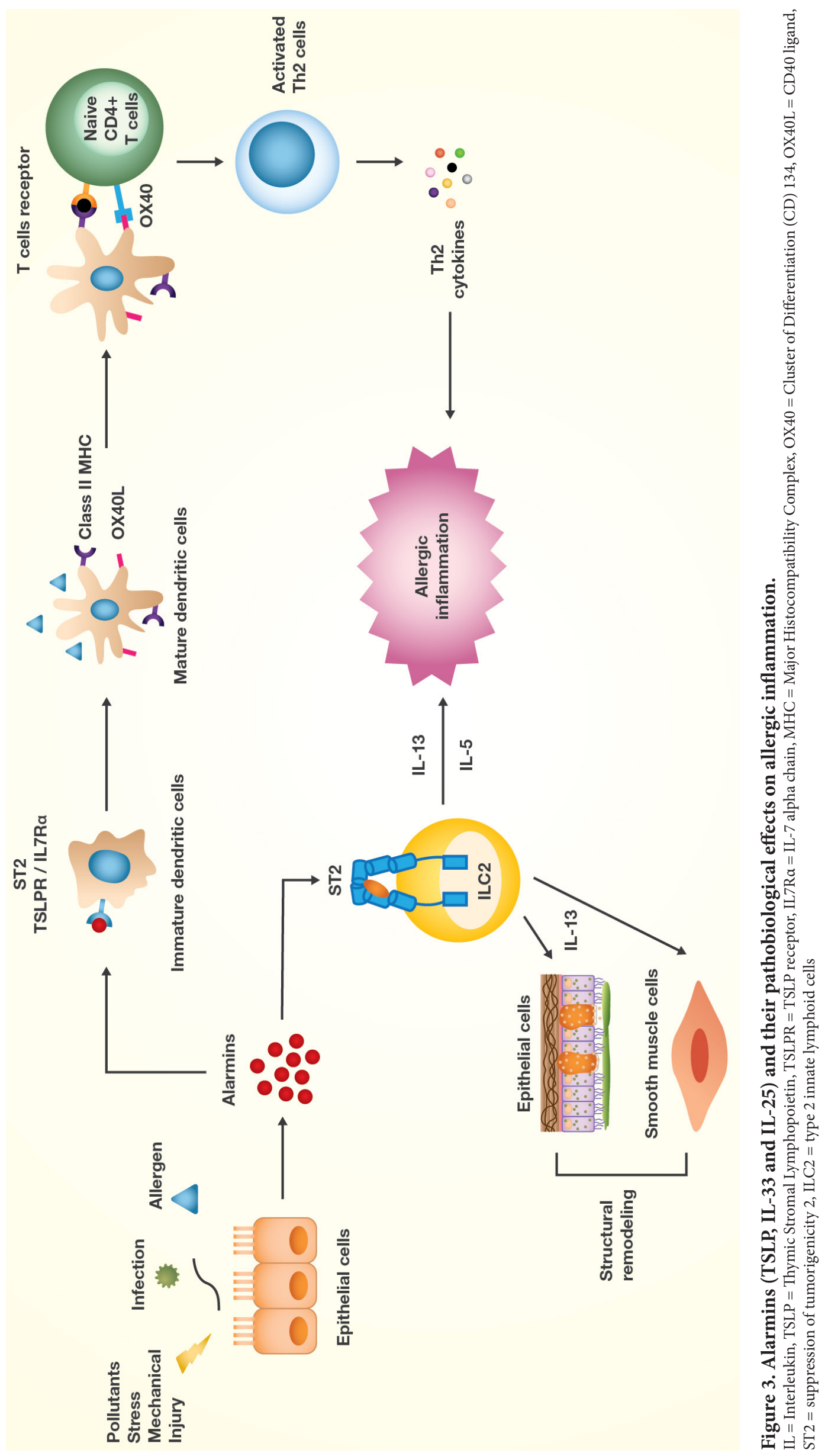


was not the primary driver of eosinophilia for poor asthma control in this group of individuals. ${ }^{15}$

Omalizumab was approved for use in patients with chronic idiopathic urticaria who remain symptomatic despite $\mathrm{H}_{1}$ -antihistamine treatment. ${ }^{16,17}$ After 12 weeks of monthly subcutaneous injections of omalizumab, patients' weekly urticaria count score was reduced by over two-thirds and more than a third were completely itch- and hive-free. A multi-centre, randomised, double blinded, placebo controlled XTEND-CIU (Xolair Treatment Efficacy of Longer Duration in Chronic Idiopathic Urticaria) trial showed that continued treatment with omalizumab prevented symptom recurrence throughout 48 weeks of treatment. ${ }^{18}$

Case history 1: A 53 year old man presented with a one year history of urticaria over the last year. The rashes were troubling him daily and were associated with intermittent swelling of his lips. His symptoms were worse if he drank red wine. He had a history of diabetes mellitus and had been taking Glucophage and Januvia for many years. Total IgE was 118 $\mathrm{kU} / \mathrm{L}$ but $\mathrm{sIgE}$ testing revealed no evidence of sensitisation to conventional allergens so might have been due to alarmin -induced production of IgE autoantibodies to cutaneous antigens, although this was unproven. There was no evidence of autoimmune disease and no history of intolerance of non-steroidal anti-inflammatory drugs. A diagnosis of chronic idiopathic urticaria was made. His symptoms were unresponsive to high doses of antihistamines, so he was started on omalizumab $300 \mathrm{mg}$ at monthly intervals. His urticaria started to improve after the first injection of omalizumab and by 3 months he was virtually asymptomatic. He continued his omalizumab for 9 months after which he was able to stop all medication.

For eczema the ADAPT randomised trial showed that 24 weeks of omalizumab therapy reduced eczema severity, improved quality of life (QoL) and was glucocorticoid-sparing in a group of difficult-to-manage severe eczematous children $(\mathrm{n}=62 ; 4-19$ years old $) .^{19}$
The treatment of food allergies with omalizumab with or without oral immunotherapy is well documented. ${ }^{20}$ In 26 peanut allergic patients omalizumab reduced the median dose of peanut provoking a positive reaction on oral challenge by 40 fold after 12 weeks of drug administration. ${ }^{21}$ Existing data suggest that combining anti-IgE and OIT is superior to anti-IgE monotherapy. ${ }^{20}$

Ligelizumab is an IgG1 anti-IgE mAb under development. Its binding affinity in vitro for IgE is 50 -fold greater than that of omalizumab and it is more potent at reducing acute $\operatorname{IgE}$ mediated responses, such as skin prick tests to conventional allergens in vivo. ${ }^{22}$ In a phase $2 \mathrm{~b}$ dose-finding trial in 382 urticarial patients, a positive response was observed at week 20 in $39 \%$ of the patients who received the $72-\mathrm{mg}$ dose of ligelizumab and in $40 \%$ of those who received the $240-\mathrm{mg}$ dose, as compared with $31 \%$ of those in the omalizumab group and $5 \%$ of those in the placebo group. ${ }^{23} \mathrm{AEs}$ were mild or moderate with the most common being upper respiratory infections (12.5\%). Ligelizumab is not currently being developed as a therapy for asthma.

\section{ANTI IL-5}

Mepolizumab (Nucala) targets human IL-5, preventing its interaction with the alpha-chain of the IL-5 receptor on eosinophils and basophils. It is an IgG1 mAb. Peripheral blood eosinophilia is typically reduced or abrogated during therapy, as with all anti IL-5 strategies. Mepolizumab $100 \mathrm{mg}$ is administered subcutaneously using prefilled syringes every 4 weeks. AEs include headache (19\%), injection site reactions (8\%), back pain (5\%) and fatigue (5\%). Two clinical trial patients developed severe Herpes Zoster infection. ${ }^{24}$

The key studies on mepolizumab in asthma are summarised in Table $1 .{ }^{25-33}$ The drug is positioned at step 5 of the GINA guidelines. It is recommended as an add-on maintenance treatment in patients with severe asthma who have an eosinophilic phenotype (> 150 peripheral blood eosinophils/ $\mu \mathrm{L})$.

Table 1. Pivotal Trials for mepolizumab on asthma.

Trial Description

DREAM $^{25}$ Design: Phase 2 PBO vs mepo $75 \mathrm{mg}$ IV; $48 \%$ reduction at week $52(p<0.0001)$ in clinically significant exacerbations; $60 \%$ reduction at week 52 in hospitalizations or emergency room visits.

Design: Phase 3 PBO vs mepo $100 \mathrm{mg}$ IV; 53\% reduction at week $32(p<0.001)$ in clinically significant exacerbations;

MENSA $^{26} 61 \%$ reduction at week $32(p=0.02)$ in hospitalizations or emergency room visits. 0.44-point improvement at week $32(p<0.001)$ in asthma control; 7.0-point improvement in SGRQ total score at week $32(p<0.001)$ $98 \mathrm{ml}$ improvement in pre-bronchodilator FEV1 at week $32(p=0.03)$.

Design: Phase 3 PBO vs mepo $100 \mathrm{mg} \mathrm{SC} ; 32 \%$ reduction at week $24(p=0.04)$ in clinically significant exacerbations; $50 \%$ reduction of median SIRIUS $^{27}$ OCS dose at week $24(p=0.007)$; 0.52 -point improvement at week $24(p=0.004)$ in asthma control; 5.8-point improvement in SGRQ total score at week $24(p=0.02)$.

Design: Phase 3b mepo $100 \mathrm{mg}$ SC; PMG OCS remained low at $2.5 \mathrm{mg}$ /day; PPG OCS reduction from $10.0 \mathrm{mg} /$ day in SIRIUS to $5.0 \mathrm{mg} / \mathrm{day}$ in COSMOS; PMG: improvement in asthma control maintained at 52 week; PPG: 0.20-point improvement in asthma control at week 52

$\begin{array}{ll}\text { COSMOS }^{28} & \text { in COSMOS; PMG: improvement in asthma control maintained at } 52 \text { week; PPG: 0.20-point improvement in asthma control at week } \\ & \text { (comparing MENSA/SIRIUS and COSMOS); PMG: improvement in pre-bronchodilator FEV1 maintained at week 52; PPG: } 100 \mathrm{ml} \\ & \text { improvement in pre-bronchodilator FEV1 at week } 52 \text { (comparing MENSA/SIRIUS and COSMOS). }\end{array}$

$\begin{array}{ll}\text { COSMOS }^{28} & \text { in COSMOS; PMG: improvement in asthma control maintained at } 52 \text { week; PPG: 0.20-point impro } \\ & \text { (comparing MENSA/SIRIUS and COSMOS); PMG: improvement in pre-bronchodilator FEV1 mai } \\ \text { improvement in pre-bronchodilator FEV1 at week } 52 \text { (comparing MENSA/SIRIUS and COSMOS). }\end{array}$

Design: Phase 3 mepo $100 \mathrm{mg} \mathrm{SC}$; $61 \%$ reduction in clinically significant exacerbations (all patients; comparing off-treatment between

COLUMBA ${ }^{29}$ DREAM and COLUMBA vs on-treatment in COLUMBA); 0.47-point mean improvement in asthma control (0.40-point improvement at week 188 to 0.66-point improvement at week 124) (comparing off-treatment between DREAM and COLUMBA vs on-treatment in COLUMBA) $144 \mathrm{ml}$ improvement in pre-bronchodilator FEV1 at week 24 but no clinically significant difference from baseline at week 20 
Table 1. (Continued)

Trial Description

Design: Phase $3 \mathrm{PBO}$ vs mepo $100 \mathrm{mg}$ SC; $58 \%$ reduction at week $24(p<0.0001)$ in clinically significant exacerbations; 68\% reduction in

MUSCA $^{30} \quad$ hospitalizations and emergency room visits at week $24(p=0.031) ; 0.4$-point improvement in asthma control at week $24(p<0.0001)$; Treatment improvement of 7.7 points in SRGQ total score from baseline at week $24(p<0.0001) ; 120$ ml improvement in pre-bronchodilator FEV1 at week $24(p=0.001)$

$\operatorname{COSMEX}^{31}$

Design: Phase 3b mepo $100 \mathrm{mg}$ SC; Annual exacerbation rate maintained from COSMOS (0.93) to COSMEX (0.93). Sustained reduction in daily OCS usage from SIRIUS (median OCS dose at weeks 124-128 is $1.3 \mathrm{mg}$ /day; sustained improvement at week 168.

OSMO $^{32} \quad$ emergency room visits at week 32; 1.45-point improvement in asthma control at week 32; 19.0-point improvement in SGRQ total score at week

Design: Phase 4 mepo $100 \mathrm{mg} \mathrm{SC;} \mathrm{64 \%} \mathrm{reduction} \mathrm{in} \mathrm{clinically} \mathrm{significant} \mathrm{exacerbations} \mathrm{at} \mathrm{week} \mathrm{32;} \mathrm{69 \%} \mathrm{reduction} \mathrm{in} \mathrm{hospitalizations} \mathrm{and}$ 32 26.2-point improvement in SGRQ symptom domain at week 32; $159 \mathrm{ml}$ improvement in pre-bronchodilator FEV1 at week 32.

REALITI-A ${ }^{33}$ Design: Phase 4 open label, single arm, real world; mepo $100 \mathrm{mg}$ SC; $77 \%$ reduction of hospitalizations and emergency room visits at week 52; $50 \%$ reduction of median OCS dose at week $52 ; 34 \%$ of patients stopped maintenance OCS at week 52.

Comparison done between mepolizumab dosing arm and placebo or baseline unless otherwise specified. Only statistical significance reported in respective published literature is included. Mepolizumab $75 \mathrm{mg}$ IV dose is equivalent in terms of bioavailability to $100 \mathrm{mg}$ SC dose. The expected completion of the REALITI-A study is 2021 and the data currently published contains the interim-analysis of the 1-year duration of the study. ACQ: Asthma control questionnaire; FEV1: forced expiratory volume in 1 second; mepo: mepolizumab; PMG: previous mepolizumab group; PPG: previous placebo group; PBO: placebo; SC: subcutaneous; SGRQ: St George's Respiratory Questionnaire.

Case history 2: An 83 year old Chinese lady had longstanding chronic asthma with 2 monthly exacerbations associated with mucopurulent sputum and intermittent rhinosinusitis. Her forced expired volume in one second (FEV1) was $82 \%$ predicted, forced expired ratio (FER) 65\% and FENO $213 \mathrm{ppb}$ (normal range $<25 \mathrm{ppb}$ ). Skin prick testing showed a small $5 \times 5 \mathrm{~mm}$ weal to Dermatophagoides farinae (DF) and Dermatophagoides pteronyssinus (DP) only. Her peripheral blood eosinophil count was $1600 / \mu \mathrm{L}(22.3 \%)$.

She had been treated for many years with all the classes of anti-asthma medications recommended for steps 4 and 5 of the GINA guidelines, but none of them reduced the frequency of her asthma exacerbations. As she exhibited an eosinophilic asthma phenotype, she was started on monthly mepolizumab $100 \mathrm{mg}$ SC. Within 2 weeks of starting treatment her FEV1 was $111 \%$ predicted, FER $72 \%$, FENO $44 \mathrm{ppb}$ and her peripheral blood eosinophil count was undetectable. She continues her monthly injections and she has been well for 6 months. The cause of her IL-5 induced eosinophilia is unknown, but alarmin-driven production of IL-5 from respiratory mucosal ILC2 cells, which are resistant to glucocorticoid inhibition, is a strong though unproven possibility.

Reslizumab (Cinqair) also binds specifically to IL-5. It is an IgG4 mAb. It is given intravenously $3 \mathrm{mg} / \mathrm{kg}$ IV over 20 to 50 minutes every 4 weeks. Intravenous reslizumab or placebo administered every 4 weeks for 1 year was compared in 2 multicentre, double-blind, parallel-group, randomised, placebo-controlled phase 3 trials. In both studies, patients receiving reslizumab had a significant reduction in the frequency of asthma exacerbations. ${ }^{34-36}$ Post-hoc analysis of this data suggests that the drug is also of benefit for those patients taking daily prednisolone, ${ }^{36}$ and also those who may not adequately respond to the fixed-dosage regimen of mepolizumab. ${ }^{38}$ AEs include oropharyngeal pain (1-10\%), elevated CPK (14\%) and anaphylaxis $(0.1-1 \%)$.

\section{ANTI IL-5 RECEPTOR}

Benralizumab (Fasenra) is an IgG1 mAb directed against the alpha-chain of the IL-5 receptor, thereby blocking the binding of IL-5. In addition, it binds simultaneously to Fc $\gamma$ RIIIa on natural killer cells triggering antibody-dependent cell-mediated cytotoxicity. This leads to amplified eosinophil apoptosis and reduced eosinophilic inflammation. This unique action of benralizumab is not observed with mepolizumab and reslizumab.

Benralizumab $30 \mathrm{mg}$ is injected SC 4 -weekly for 8 weeks followed by $30 \mathrm{mg}$ every 8 weeks thereafter. AEs are mild and include headache $(8.6 \%)$, pharyngitis $(4 \%)$, arthralgia $(3.9 \%)$, cough (3.3\%) and injection site reactions (2.2\%).

The key studies on benralizumab in asthma are summarised in Table 2..$^{39-42}$ The drug is also positioned at step 5 of the GINA guidelines and, identical to mepolizumab and reslizum$\mathrm{ab}$, is recommended as an add-on maintenance treatment of patients with severe asthma with an eosinophilic phenotype (> 150 peripheral blood eosinophils/ $\mu \mathrm{L}$ ).

Table 2. Pivotal trials on benralizumab for asthma.

Benralizumab significantly decreased the annual asthma exacerbation rate compared with placebo at week 48 , for the Q8W cohort, the rate ratio versus placebo was $0.49(0.37-0.64 ; p<0.0001)$

Reduced asthma exacerbations leading to emergency department visits or hospital admissions compared with placebo treatment (rate ratio $0.37,95 \%$ CI 0.20-0.67; $p=0.0010$ ).

SIROCCO $^{39} \quad$ Significantly improved pre-bronchodilator FEV1 in patients at week 48 compared with placebo.

Reductions in asthma symptoms (Total Asthma Score) at week 56 and 48 compared to patients receiving placebo. Similar improvement was observed for the Asthma Control Questionnaire-6 (ACQ-and Standardized Asthma Quality of Life Questionnaire for 12 Years and older (AQLQ(s) +12). 
Table 2. (Continued)

Trial Description

56 weeks of treatment with benralizumab Q8W resulted in approximately 28\% lower in annual exacerbation rate compared with placebo for patients receiving high-dosage inhaled corticosteroids plus LABA with baseline blood eosinophils $\geq 300$ cells per uL

CALIMA $^{40} \quad$ Significant increase in pre-bronchodilator FEV1, compared with placebo for patients receiving high-dosage inhaled corticosteroids plus LABA with baseline blood eosinophils $\geq 300$ cells per $\mathrm{uL}$. Improvements in pre-bronchodilator FEV1 were present within 4 weeks of treatment start and were maintained throughout the entire treatment period.

ZONDA $^{41} \quad$ Benralizumab treatment (28 week) significantly reduced the median final oral glucocorticoid doses from baseline by $75 \%$, as compared with a reduction of $25 \%$ in the oral glucocorticoid doses in the placebo group $(P<0.0001$ for both comparisons).

$753(72 \%)$ of 1046 patients with blood eosinophil counts of 300 cells per uL or greater at baseline did not have asthma exacerbations during benralizumab treatment. The pre-bronchodilator FEV1 values, ACQ-6 and AQLQ(s) +12 scores for patients who had received benralizumab in SIROCCO or CALIMA were maintained into the second year of treatment.

LABA = Long acting beta 2 agonist

Case History 3: A 55 year old lady with asthma, chronic rhinosinusitis and nasal polyposis had been receiving frequent courses of prednisone 4-5 times a year. Her skin prick tests to ragweed pollen and house dust mites (HDM) were positive and her total serum IgE was $500 \mathrm{kU} / \mathrm{L}$. Her asthma control had been maintained on daily $20 \mathrm{mg}$ prednisone, budesonide $2400 \mu \mathrm{g} /$ fomoterol $24 \mu \mathrm{g}$ and nasal budesonide saline rinses. Her blood eosinophil count was $900 / \mu \mathrm{L}$ and sputum eosinophil count was $60 \%$ with many free eosinophil granules. Her Asthma Control Questionnaire-5 (ACQ-5) score was 3.4 .

She had previously failed to show any clinical improvement following one year of treatment with omalizumab. In the context of a clinical trial, she received mepolizumab $100 \mathrm{mg} \mathrm{SC}$ for a year and her blood eosinophil counts were normalised. However, on reducing her prednisone to $12.5 \mathrm{mg}$ daily, she had an exacerbation of asthma that was associated with a sputum eosinophil count of $20 \%$ with many free granules. Her sinus CT showed bilateral ethmoid, maxillary and sphenoid mucosal thickening without polyposis.

She then participated in a clinical trial of reslizumab $3 \mathrm{mg} /$ $\mathrm{kg}$ IV monthly for 4 months. At the end of the treatment, her sputum eosinophil count had reduced to $8 \%$ but still with many free granules. Her blood eosinophils remained undetectable. On gradual reduction of prednisone to $7.5 \mathrm{mg}$ daily, she developed an exacerbation of her asthma which was associated with both blood and sputum eosinophilia, and her prednisone dosage had to be increased up to $12.5 \mathrm{mg}$ daily.

She was switched to receive benralizumab $30 \mathrm{mg}$ SC monthly for 3 months and then every alternate month. Her prednisone dosage was slowly tapered in a controlled manner after her $2^{\text {nd }}$ dose of benralizumab. Following one year of treatment, she was completely weaned off prednisone and was maintained on $400 \mu \mathrm{g}$ of budesonide and $12 \mu \mathrm{g}$ of formoterol daily. Her spirometry was normal and FENO was 15 ppb. Blood and sputum eosinophils were undetectable and her ACQ-5 score was zero. However, her sinuses were still not optimally controlled.

This case suggests that for adequate asthma control and a prednisone-sparing effect, an intervention needs to control both peripheral blood and airway eosinophilia. Mepolizumab and reslizumab bind to IL-5 while benralizumab is an IL-5 receptor antagonist as well as promoting eosinophil apoptosis, so while the drugs are related and are all anti IL-5 biologicals, they are not identical in their modes of action. Thus it may still benefit patients to have a trial of another related $\mathrm{mAb}$ with a different mode of action even when a previous course of therapy with other anti IL-5 biologicals was ineffective, provided the reason for inadequate asthma control is ongoing eosinophilia. It is important to assess this as exacerbations on anti-eosinophilic biologicals do not necessarily have to be eosinophilic. Some of them, particularly on benralizumab, for currently unknown reasons, may be neutrophilic due to infective bronchitis.

\section{ANTI IL-4/13 RECEPTOR}

Dupilumab (Dupixent) is a receptor antagonist and binds to the alpha subunit of the IL-4 receptor (IL-4Ra). As both IL-4 and IL-13 signal through IL-4Ra, dupilumab modulates both pathways. The pivotal clinical trials on eczema are shown in Table $3 .^{43-47}$ It is indicated for the treatment of patients with moderate-to-severe eczema whose disease is not adequately controlled. The most frequent AEs of about $10 \%$ are injection site reactions and conjunctivitis.

Table 3. Pivotal trials on dupilumab for eczema.

671 patients $>18$ years old with moderate-to-severe eczema that was inadequately controlled by or medically inadvisable for treatment with topical therapy were enrolled in SOLO 1 and 708 in SOLO 2. In SOLO 1, the primary outcome occurred in $38 \%$ who received dupilumab every other week and in $37 \%$ who received dupilumab weekly, as compared with $10 \%$

SOLO 1 and SOLO $2^{43}$ who received placebo $(P<0.001)$. The results were similar in SOLO 2. Improvement from baseline to week 16 of at least $75 \%$ on the Eczema Area and Severity Index was reported in more patients who received dupilumab $(P<0.001)$. Injection-site reactions and conjunctivitis were more frequent in the dupilumab groups. 
Table 3. (Continued)

Trial

Description

To assess dupilumab administered concomitantly with TCS for 52 weeks in patients with moderate-to-severe eczema ( $\geq 18$ years old). 319 were randomly assigned to dupilumab qw plus topical corticosteroids, 106 to dupilumab q2w plus topical corticosteroids, and 315 to placebo plus topical corticosteroids. At week 16, more patients who received dupilumab achieved the co-primary endpoints of IGA $0 / 1(39 \%)(p<0.0001)$ and EASI-75 (64\% and 69\% vs 23\%, respectively, $p<0.0001)$. Week 52 results were similar.

LIBERTY AD CAFÉ ${ }^{45}$

To evaluate dupilumab in the difficult-to-treat patient population of adults with eczema with inadequate response to or intolerance of cyclosporine (CsA), or for whom CsA is medically inadvisable. 110 patients received $300 \mathrm{mg}$ dupilumab once-weekly, 107 received it every two weeks, and 108 received placebo once-weekly. All participants used topical corticosteroids during the 16-week study. By Week 16, 59\% to $62 \%$ of dupilumab-treated participants achieved $75 \%$ or greater improvement in EASI, versus $29.6 \%$ of people on placebo. Dupilumab also improved itching, mood, and quality of life.

Phase 3 trial to investigate the efficacy and safety of dupilumab monotherapy in adolescents ( $\geq 12-17$ years old) with

LIBERTY AD ADOL ${ }^{46}$ moderate-to-severe eczema inadequately controlled by topical therapies. The results from this pivotal trial led to the US FDA approval of dupilumab in this patient population. Drug treatment resulted in clinically relevant and statistically significant improvements in eczema and QoL in adolescents with moderate-to severe eczema, with an acceptable safety profile.

Phase 3 trial to evaluate maintenance of clinical response and long term safety of dupilumab monotherapy for an additiona 3 years at $300 \mathrm{mg}$ weekly (qw) or q2w, or less-frequent regimens, or drug withdrawal in patients with eczema who had

LIBERTY AD SOLO-CONTINUE ${ }^{47}$ previously achieved high-level responses at week 16 in LIBERTY AD SOLO 1 or LIBERTY SOLO 2. Continued response over time was most consistently maintained with dupilumab qw/2w with no safety signals. Longer dosing intervals and especially placebo was less effective.

TCS = topical corticosteroid. EASI = Eczema Area and Severity Index. EASI-75 = 75\% reduction in EASI from baseline. IGA = Investigator's Global Assessment. QoL $=$ Quality of Life.

Case history 4: A 25 year old Chinese student had longstanding severe eczema since the age of 2 years old. He had been treated intensively with emollients, topical steroids, calcineurin inhibitors, topical and oral antibiotics and antihistamines on many occasions but without sustained improvement. His SCORAD (SCORing Atopic Dermatitis) score was 69.35. He was sleeping poorly and could not concentrate on his studies because of the constant itching and discomfort. His total IgE was $1515 \mathrm{kU} / \mathrm{L}$ and he was allergic to DF, DP and Blomia tropicalis (BT). He was commenced on dupilumab 600 mg SC stat and then $300 \mathrm{mg}$ SC every two weeks thereafter. His eczema improved after his first injection of dupilumab. His SCORAD score was 18.25 at 4 months after starting his treatment. He could sleep better and was able to concentrate on his studies achieving a distinction grade in one of his final examinations.
The key studies on dupilumab in asthma and chronic rhinitis with nasal polyposis are shown in Table $4 .^{48-51}$ It is recommended for use as an add-on maintenance treatment for patients with moderate-to-severe asthma with an eosinophilic phenotype, or with glucocorticoid-dependent asthma regardless of phenotype (step 5 of GINA guidelines).

Case history 5: A 66 year old Chinese man had rhinitis since childhood. Ingestion of aspirin caused wheezing and eye swelling when he was 60 years old and asthma started to trouble him 2 years later. The patient's most disturbing symptom was a loss of his sense of smell and taste because he was a food and wine connoisseur. His sense of smell would return briefly if he took prednisolone $25 \mathrm{mg}$ daily for 2 weeks but it would be lost again when the drug was stopped. His total $\operatorname{IgE}$ was $859 \mathrm{kU} / \mathrm{L}$ and his skin prick test was only barely positive

Table 4. Pivotal trials on dupilumab for asthma and chronic rhinosinusitis with nasal polyposis.

LIBERTY ASTHMA VENTURE $^{52}$

\section{LIBERTY ASTHMA QUEST ${ }^{53}$}

( ${ }^{*}$ Add-on analysis from QUEST) $)^{54}$

\section{LIBERTY NP SINUS-24 and} LIBERTY NP SINUS-52 5

\begin{abstract}
A steroid-sparing study to evaluate the percentage reduction in oral glucocorticoid dose from baseline to Week 24 while asthma control was maintained. ( $\geq 12$ years old). Dupilumab treatment reduced oral glucocorticoid use while decreasing the rate of severe exacerbations and increasing the FEV1.
\end{abstract}

To evaluate the efficacy of dupilumab in patient with persistent asthma, safety and tolerability of dupilumab, the effect of dupilumab in improving patient-report outcomes. ( $\geq 12$ years old). Dupilumab had significantly lower rates of severe asthma exacerbation, as well as better lung function and asthma control. Greater benefits were seen in patients with higher baseline levels of eosinophils.

To assess dupilumab's effect on key asthma outcomes in QUEST patients with/without evidence of allergic asthma (total serum IgE $\geq 30 \mathrm{IU} / \mathrm{mL}$ and $\geq 1$ perennial aeroallergen-specific $\operatorname{IgE} \geq 0.35 \mathrm{kU} / \mathrm{L}$ at baseline). ( $\geq 12$ years old). Dupilumab reduced severe exacerbation rates, improved FEV1 and asthma control, and suppressed type 2 inflammatory biomarkers.

To determine the efficacy and safety of dupilumab when added to standard therapy (INCS) in adults with severe CRSwNP uncontrolled by standard of care, including patients with a history of comorbid asthma and/ or NSAID-ERD. ( $\geq 18$ years old). In adult patients with severe CRSwNP, dupilumab reduced polyp size, sinus opacification, and severity of symptoms and was well tolerated.

INCS = intranasal corticosteroid. NSAID-ERD = non-steroidal anti-inflammatory drug- exacerbated respiratory disease. CRSwNP = Chronic Rhinosinusitis with Nasal Polyposis 
to $\mathrm{BT}(3 \times 3 \mathrm{~mm}$ weal). His FEV1 was $68 \%$ predicted, FER $66 \%$, FENO $52 \mathrm{ppb}$. His blood eosinophil count was $70 / \mu \mathrm{L}$. Nasendoscopy revealed that his nose was packed with polyps. He had been treated intensively over the previous 6 years with inhaled asthma medications, theophyllines, montelukast, nasal washes, nasal steroids, intermittent courses of oral steroids and even mepolizumab, but none of them provided any sustained improvement. His ENT specialist advised against surgery because of the high likelihood of recurrence of the polyps following surgical removal.

His aspirin exacerbated respiratory disease (AERD) was treated with dupilumab $600 \mathrm{mg}$ SC stat followed by $300 \mathrm{mg}$ SC at 2 weekly intervals. Within 2 weeks of his first injection of dupilumab his sense of smell was normal. Nasendoscopic examination performed at 4 months showed that the nasal polyps had disappeared. His recent FEV1 was $85 \%$ predicted, FER $67 \%$ and FENO 36 ppb.

\section{ANTI IL-13}

Tralokinumab neutralises IL-13. In a phase 2b study, 204 adults with eczema were treated with increasing doses of the $\mathrm{mAb}$ or placebo every 2 weeks for 12 weeks with concomitant topical glucocorticoids. ${ }^{52}$ Subjects injected with tralokinumab $300 \mathrm{mg}$ SC showed improvements in SCORAD, Dermatology Life Quality Index and pruritus. Upper respiratory infections were the most frequent $\mathrm{AE}(3.9 \%)$.

Lebrikizumab binds to free IL-13 with very high affinity and inhibits the formation of the IL-13Ra/IL-4Ra heterodimer complex and downstream signalling. The mAb was tested in a multi-centre, randomised, double blind, placebo controlled, phase $2 \mathrm{~b}$ trial over 16 weeks in 280 adult patients with moderate to severe eczema. ${ }^{53}$ The drug effected significant and dosedependent improvements at $125 \mathrm{mg}$ injected SC every 4 weeks $(\mathrm{p}=0.017), 250 \mathrm{mg}$ injected SC every 2 weeks $(\mathrm{p}=0.002)$ and $250 \mathrm{mg}$ administered SC at 4 weekly intervals $(\mathrm{p}=0.0005)$. It is now in phase 3 trials. The most common AEs reported ranged from $3.1-7.5 \%$ and included upper respiratory tract infection, nasopharyngitis, headache and injection site pain. Early phase 2 studies showed it to be effective in asthma, ${ }^{54}$ but it did not meet pre-specified outcomes in late phase 3 trials, ${ }^{55}$ so is not being developed any further to treat asthma.

\section{ANTI TSLP}

Tezepelumab is a human mAb that competes with the receptor binding site on TSLP. In 550 adult patients with moderate-to-severe asthma, the drug reduced asthma exacerbations in the 52 week trial by $61 \%, 71 \%$ and $66 \%$ at $280 \mathrm{mg}$ injected SC every two weeks, $210 \mathrm{mg}$ every 4 weeks and $70 \mathrm{mg}$ every 4 weeks respectively. ${ }^{56}$ It appeared to be efficacious irrespective of asthma phenotype and is currently in phase 3 trials. Three serious adverse events were recorded: two (pneumonia and stroke) occurred in the same patient and one subject developed the Guillain-Barré syndrome. The rates of discontinuation due to AEs were $1.2 \%$ among patients and $0.7 \%$ in the placebo group.

\section{ANTI IL-22}

Serum IL-22 levels are increased in patients with eczema ${ }^{57}$ and expression in the skin of mice caused an atopic dermatitis-like phenotype. ${ }^{58}$ Fezakinumab, which is an anti IL-22 mAb, was tested in a randomised, double-blind, placebo-controlled phase 2a trial in eczema patients as intravenous monotherapy every 2 weeks for 10 weeks with follow-up assessments until 20 weeks. In the severe subset the improvement in SCORAD was significantly stronger in the drug-treated patients at 12 weeks and 20 weeks $(P=0.010)$. Improvements in body surface area involvement were significantly stronger in the drug-treated patients $(\mathrm{P}=0.009) .{ }^{59}$ Commonest $\mathrm{AE}$ was upper respiratory tract infections $(10 \%)$.

\section{ANTI IL-31}

IL-31 is released from Th2 cells and mast cells following cutaneous penetration by antigens. It stimulates sensory neurons and contributes to itching in eczema. Nemolizumab is directed against the IL-31Ra subunit so blocks IL-31 signalling. ${ }^{60}$ A 24-week, randomised, double-blind, multicentre study of nemolizumab (10 mg, $30 \mathrm{mg}$ and $90 \mathrm{mg}$ ) SC improved the Eczema Area and Severity Index, the peak pruritus numeric rating scale, and the Investigator's Global Assessment, with the 30-mg dose being most effective. It is now in phase 3 studies. AEs included nasopharyngitis, eczema exacerbation, increased $\mathrm{CPK}$, upper respiratory infection, headache, peripheral oedema and impetigo.

\section{ANTI IL-33}

IL-33, an alarmin, is expressed in epithelial cells, endothelial cells and lymphoid organs. It is rapidly released by pollutants, allergen or infection. It binds to the receptors ST2, also known as IL-1RL1 (interleukin 1 receptor-like 1) and IL-1RacP (IL-1 receptor accessory protein), both of which are expressed by innate immune cells (ILC2) and Th2 cells. It stimulates production of IL-5 and IL-13. (Figure 2). Recent evidence suggests that TSLP and IL-33 may reciprocally promote each other's lung protein expression and ILC2 receptor expression to enhance innate type- 2 airways inflammation. ${ }^{61}$

Etokimab is an anti-IL-33 $\mathrm{mAb}$ in phase $2 \mathrm{~b}$ development and its half-life is 15.5 days. A single dose, 6-week, placebo -controlled phase 2a study in 15 adults with severe peanut allergy showed efficacy. On days 15 and 45 after dosing with etokimab $300 \mathrm{mg} \mathrm{IV}, 73 \%$ and $57 \%$ respectively of the patients tolerated ingestion of $275 \mathrm{mg}$ of peanut protein. No subject in the placebo group passed the peanut challenge. ${ }^{62}$ Peanut-specific IgE was significantly reduced in the active group compared with the placebo group on day $15(P=0.014)$. Thus a single dose of etokimab desensitised many peanutallergic patients for at least 6 weeks. No patients reported AEs. The mechanism of efficacy is being investigated but could reflect, at least in part, attenuation of those downstream allergic pathways dependent upon IL-33 (IL-5, IL-9, IL-13, IL-4) in $\mathrm{CD} 4^{+} \mathrm{T}$ cells. It has also been proposed that the effect on IgE synthesis could be due to the blockade of IL-33 stimulating ST2 on B cells. 
Proposed pragmatic scheme for selecting a $m A b$ to treat severe asthma

The majority of asthmatic patients will respond to the traditional guidelines-based therapies but 5-10\% will fail to improve despite optimisation of compliance and management of co-morbidities. These patients comprise up to $95 \%$ of health care costs and economic burden. The advent of biologicals introduces a new paradigm of targeted medicine which could potentially help these patients with severe asthma.

Some indirect comparative studies between the effectiveness of different $\mathrm{mAbs}$ have been published for asthma, ${ }^{63-65}$ in contrast to biologicals for other allergic diseases which have not been similarly compared. Even in asthma more independent research employing direct head-to-head comparisons is urgently needed. In addition while some biomarkers have been identified that define different disease endotypes in asthma, or at least endotypes likely to respond to anti-IL-5 strategies, there are few or no biomarkers used in clinical practice that will predict responsiveness to targeted biologicals for the other diseases discussed in this review.
Until more data are forthcoming, a pragmatic framework for targeted therapy is proposed based on a patient's biomarkers, namely peripheral blood eosinophil count, FENO, induced sputum analysis, total IgE, the physiological measurement of airway hyperresponsiveness and prednisolone usage, to aid selection of the $\mathrm{mAb}$ to use in severe uncontrolled asthma. (Figures 4A and 4B) Apart from quantitative sputum cytometry, the other biomarkers are readily available in virtually all Centres.

It is suggested that in the presence of a high peripheral blood and sputum eosinophilia that may or may not be associated with raised FENO, an anti IL-5 approach could be an appropriate choice. (Figure 4A) It is worth noting that elevated FENO is not a predictor of response to anti IL5 mAbs and that FENO is not reliably reduced with anti IL5 therapies. ${ }^{66}$ In general with anti IL-5 strategies the higher the blood eosinophil counts, the better the clinical response. It appears that eosinophil counts of $>300$ cells $/ \mu \mathrm{L}$ in the context of asthma and not some other external causes are more likely to be truly indicative of the eosinophil being a key effector cell in the patient's asthma pathobiology.

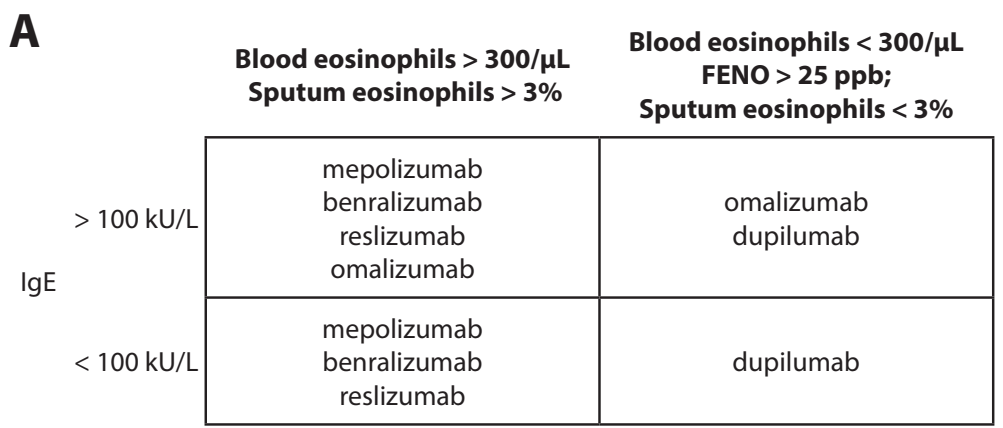

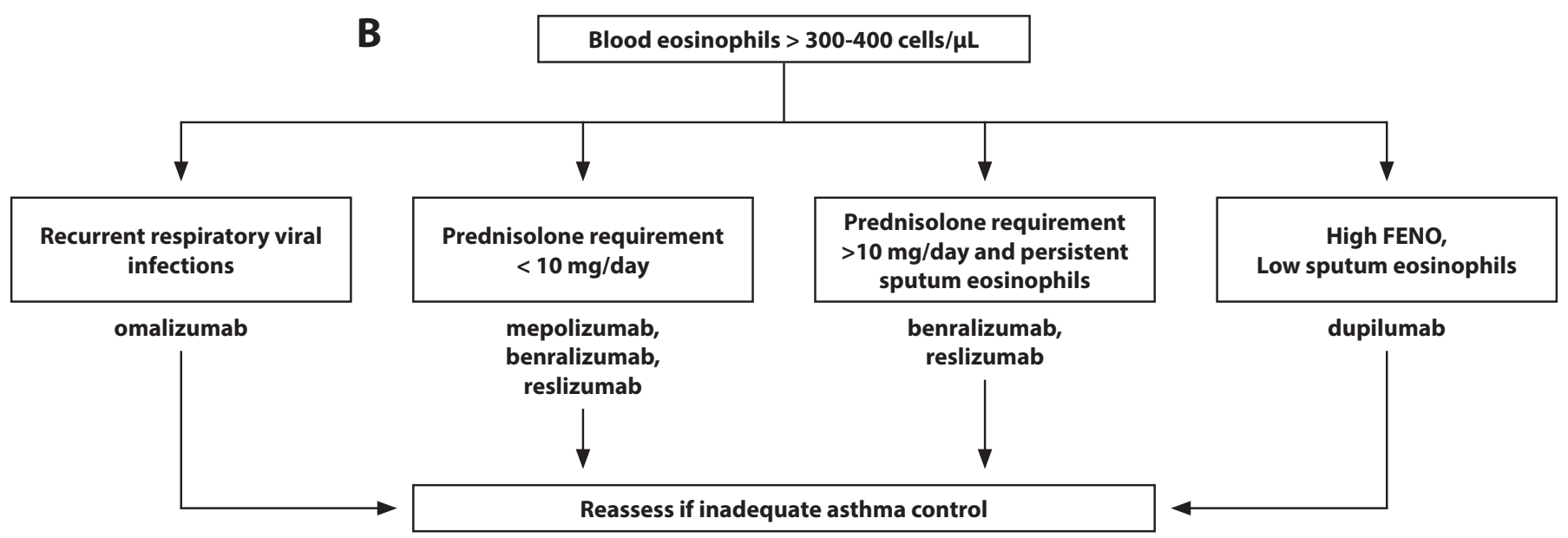

Figure 4. Proposed framework for selecting a biological treatment for asthma based on (A) peripheral eosinophil count, FENO, induced sputum cytometry and total IgE concentrations. If patient remains symptomatic despite normalizing blood and sputum eosinophil counts, symptoms may be driven by airway hyperresponsiveness. (B) blood eosinophils, FENO and prednisolone dosage. There are no head to head comparisons or cross-over studies of patients who had failed on one therapy. Panel B is modified from reference 69. 
With respect to the selection of which anti IL-5 mAb, all molecules are equally effective in reducing exacerbations by $50-60 \%$ in most patients with severe asthma who are on high dose of inhaled corticosteroids. Three doses of benralizumab are injected in the first 2 months then one dose is given every 2 months, whereas mepolizumab is given monthly, and reslizumab is given monthly intravenously, so the final decision on which $\mathrm{mAb}$ to use may depend on patient preferences. The magnitude of the treatment effects on reductions in exacerbations and prednisolone-sparing, at least with the current recommended dosing regimens in the prednisolone-dependent patients may be greater with benralizumab and dupilumab than with mepolizumab but more research is required to substantiate this clinical observation. As the action of benralizumab involves NK cells, it may not be the first choice if the patient has reduced NK cell counts or has a predisposition to airway infections, but this hypothesis also requires further prospective examination.

The presence of recurrent respiratory viral infections with or without high IgE and severe allergies could encourage the use of omalizumab. (Figure 4B) In the absence of an eosinophilia, especially if there is accompanying eczema, chronic rhinosinusitis and nasal polyposis with or without NSAID sensitivity, and particularly when associated with raised FENO, ${ }^{48}$ airway mucus ${ }^{67,68}$ and airway hyperresponsiveness, dupilumab may be the best option. Novel imaging techniques such as noble gas functional MRI and dual-source airway CT scans may enable a determination of intraluminal mucus plugging but these are not readily available in most Centres. In patients requiring $<10 \mathrm{mg} /$ day of prednisolone, mepolizumab, benralizumab or reslizumab could be the drugs of choice, whereas for those taking $>10 \mathrm{mg} /$ day prednisolone with accompanying persistent sputum eosinophilia, benralizumab or reslizumab may be better options. ${ }^{69}$ (Figure 4B)

Persistent sputum eosinophilia despite normalising blood eosinophilia in a symptomatic patient may reflect inadequate dosing, neutralising antibodies, or other causes of eosinophil recruitment. On-going symptoms and poor asthma control may also reflect recurrent respiratory tract infection (reflected by neutrophilic bronchitis) rather than lack of efficacy of the anti IL-5 mAb. Mepolizumab, benralizumab and dupilumab are untested for the management of acute asthma exacerbations.

Depletion of eosinophils inevitably raises concerns about the safety of long term usage of anti IL-5 drugs. Clinical and experimental evidence from eosinopenic human subjects and murine strains devoid of eosinophils have not, however, suggested any increased susceptibility to infections, cancer or other abnormalities of global health. ${ }^{70}$ Nonetheless helminthic infections should be treated prior to commencing anti IL-5 therapies and some clinicians, especially in endemic regions, advocate screening of patients for pre-existing helminthic infections, for example with a blood test for Strongyloides IgG. If a helminthic infection is contracted during anti IL-5 therapy, the drug should be stopped if anti helminthic treatment is not effective. In a small proportion of severe prednisolonedependent patients, inadequate dosing with anti IL5 mAb may exacerbate asthma secondary to the effects of IL-5 anti IL5 $\mathrm{mAb}$ immune complexes activating complement.

\section{Conclusions}

This is an exciting time for asthma and allergy. Omalizum$\mathrm{ab}$, mepolizumab, benralizumab and reslizumab are already licensed for the treatment of severe uncontrolled asthma. Omalizumab is used for urticaria and its efficacy in paediatric eczema looks promising. Dupilumab is licensed for treating eczema, asthma and chronic rhinosinusitis with nasal polyposis. In addition there are many other biologicals in the pipeline, so the demand for effective and targeted $\mathrm{mAbs}$ to treat allergic diseases will surely grow. The introduction of potent and specific non-allergen directed biological treatments with or without new allergen-specific desensitisation strategies, which are also in the advanced stages of development, could herald an unprecedented era of personalised medicine for allergic diseases. The on-going challenge is to identify biomarkers that define disease endotypes which can then be used to exploit these specific and potent biologicals for targeted therapy in the context of precision medicine.

\section{Conflict of interest} clare.

The authors have no potential conflicts of interests to de-

\section{Acknowledgements}

The information provided by Steve T. Luk of GSK HK, Sophia Liang of AstraZeneca and Kathleen Lau of Sanofi was derived from published literature in response to a personal enquiry from THL. Funding was not provided by the companies and they did not contribute to the review in any other way.

Authors contributed equally to the writing of the manuscript.

\section{References}

1. Lambrecht BN, Hammad H. The immunology of asthma. Nat Immunol. 2014;16(1):45-56.

2. Eyerich S, Metz M, Bossios A, Eyerich K. New biological treatments for asthma and skin allergies. Allergy [Preprint]. 2019 [cited 2020 Jan 5]:[15 p.]. Available from: https://doi.org/10.1111/all.14027

3. Bianchi ME. DAMPs, PAMPs and alarmins: all we need to know about danger. J Leukoc Biol. 2007;81(1):1-5

4. Liu YJ, Soumelis V, Watanabe N, Ito T, Wang YH, Malefyt Rde W, et al. TSLP: an epithelial cell cytokine that regulates $\mathrm{T}$ cell differentiation by conditioning dendritic cell maturation. Annu Rev of Immunol. 2007;25: 193-219.

5. Miller AM. Role of IL-33 in inflammation and disease. J Inflamm (Lond). 2011;8(1):22.

6. Divekar R, Kita H. Recent advances in epithelium-derived cytokines (IL-33, IL-25, and thymic stromal lymphopoietin) and allergic inflammation. Curr Opin Allergy Clin Immunol. 2015;15(1):98-103.

7. Fort MM, Cheung J, Yen D, Li J, Zurawski SM, Lo S, et al. IL-25 induces IL-4, IL-5, and IL-13 and Th2-associated pathologies in vivo. Immunity. 2001;15(6):985-95.

8. Smith S, Chen R, Kjarsgaard M, Huang C, Oliveria J, O'Byrne P, et al Increase numbers of activated group 2 innate lymphoid cells in the airways of patients with severe asthma and persistent airway eosinophilia. J Allergy Clin Immunol. 2016;137(1):75-86.

9. Sehmi R, Smith S, Kjarsgaard M, Radford K, Boulet L, Lemiere C, et al Role of local eosinophilopoietic processes in the development of airway eosinophilia in prednisone-dependent severe asthma. Clin Exp Allergy. 2016;46(6): 793-802

10. Carlos Cardet JC, Casale TB. New insights into the utility of omalizumab. J Allergy Clin Immunol. 2019; 143(3):923-6.e.1. 
11. Global Initiative For Asthma [Internet]. Fontana: Global Strategy for Asthma; c2019 [cited 2019 Nov 29]. Global Strategy for Asthma Management and Prevention; USA;2019, [about one screen]. Available from: https://ginasthma.org/gina-reports/.

12. Al Said A, Cushen B, Costello RW. Targeting patients with asthma for omalizumab therapy: choosing the right patient to get the best value for money. Ther Adv Chronic Dis. 2017;8(2-3):31-45.

13. Pillai P, Chan YC, Wu SY, Ohm-Laursen L, Thomas C, Durham SR, et al. Omalizumab reduces bronchial mucosal IgE and improves lung function in non-atopic asthma. Eur Respir J. 2016; 48(6):1593-601.

14. Normansell R, Walker S, Milan S, Walters E, Nair P. Omalizumab for asthma in adults and children. Cochrane Database Syst Rev. 2014; CD003559.

15. Mukherjee M, Kjarsgaard M, Rasford K, Huang C, Leigh R, Dorscheid D, et al. Omalizumab in patients with severe asthma and persistent sputum eosinophilia. Allergy Asthma Clin Immunol. 2019;15:21.

16. Saini SS, Bindslev-Jensen C, Maurer M, Grob JJ, Bulbul Baskan E, Bradley MS, et al. Efficacy and safety of omalizumab in patients with chronic idiopathic/spontaneous urticaria who remain symptomatic on $\mathrm{H} 1$ antihistamines: a randomized, placebo-controlled study. J Invest Dermatol. 2015;135(1):67-75.

17. Maurer M, Rosen K, Hsieh HJ, Saini S, Grattan C, Gimenez-Arnau A, et al. Omalizumab for the treatment of chronic idiopathic or spontaneous urticaria. N Engl J Med. 2013;368(10):924-35.

18. Maurer M, Kaplan A, Rosen K, Holden M, Iqbal A, Trzaskoma BL, et al. The XTEND-CIU study: Long-term use of omalizumab in chronic idiopathic urticaria. J Allergy Clin Immunol. 2018;141(3):1138-9 e7.

19. Chan S, Corneliu V, Cro S, Harper JI, Lack G. Treatment effect of omalizumab on severe pediatric atopic dermatitis: the ADAPT randomised clinical trial. JAMA Pediatrics. 2020;174(1):29-37.

20. Manohar M, Nadeau KC. The Potential of Anti-IgE in Food Allergy Therapy. Curr Treat Options Allergy. 2014;1(2):145-56.

21. Lee TH, Chan JKC, Lau PC, Luk WP, Fung LH. Peanut allergy and oral immunotherapy. Hong Kong Med J. 2019;25(3):228-34.

22. Arm JP, Bottoli L, Skerjanec A, Floch D, Groenewegen A, Maahs S, et al. Pharmacokinetics, pharmacodynamics and safety of QE 031 (ligelizumab), a novel high-affinity anti-IgE antibody in atopic subjects. Clin Exp Allergy. 2014; 44: 1371-85.

23. Maurer M, Gimenez-Arnau AM, Sussman G, Metz M, Baker DR, Bauer A, et al. Ligelizumab for Chronic Spontaneous Urticaria. N Engl J Med. 2019;381(14):1321-32

24. Nucala [package insert]. Philadelphia, PA: GlaxoSmithKline LLC; 2015. Available from: https://www.accessdata.fda.gov/drugsatfda_docs/label/ 2015/125526Orig1s000Lbl.pdf

25. Pavord ID, Korn S, Howarth P, Bleecker ER, Buhl R, Keene ON, et al. Mepolizumab for severe eosinophilic asthma (DREAM): a multicentre, double-blind, placebo-controlled trial. Lancet. 2012;380(9842):651-9.

26. Ortega HG, Liu MC, Pavord ID, Brusselle GG, FitzGerald JM, Chetta A, et al. Mepolizumab treatment in patients with severe eosinophilic asthma. N Engl J Med. 2014;371(13):1198-207.

27. Bel EH, Wenzel SE, Thompson PJ, Prazma CM, Keene ON, Yancey SW, et al. Oral glucocorticoid-sparing effect of mepolizumab in eosinophilic asthma. N Engl J Med. 2014;371(13):1189-97.

28. Lugogo N, Domingo C, Chanez P, Leigh R, Gilson MJ, Price RG, et al. Long-term efficacy and safety of mepolizumab in patients with severe eosinophilic asthma: A multi-center, open-label, phase IIIb study. Clin Ther. 2016;38(9):2058-70 e1.

29. Khatri S, Moore W, Gibson PG, Leigh R, Bourdin A, Maspero J, et al. Assessment of the long-term safety of mepolizumab and durability of clinical response in patients with severe eosinophilic asthma. J Allergy Clin Immunol. 2019;143(5):1742-51 e7.

30. Chupp GL, Bradford ES, Albers FC, Bratton DJ, Wang-Jairaj J, Nelsen LM, et al. Efficacy of mepolizumab add-on therapy on health-related quality of life and markers of asthma control in severe eosinophilic asthma (MUSCA): a randomised, double-blind, placebo-controlled, parallel-group, multicentre, phase 3b trial. Lancet Respir Med. 2017;5(5):390-400.

31. Khurana S, Brusselle GG, Bel EH, FitzGerald JM, Masoli M, Korn S, et al. Long-term safety and clinical benefit of mepolizumab in patients with the most severe eosinophilic asthma: The COSMEX Study. Clin Ther. 2019;41(10):2041-56 e5.
32. Chapman KR, Albers FC, Chipps B, Munoz X, Devouassoux G, Bergna $\mathrm{M}$, et al. The clinical benefit of mepolizumab replacing omalizumab in uncontrolled severe eosinophilic asthma. Allergy. 2019;74(9):1716-26.

33. Harrison T, Canonica GW, Gemzoe K, Maxwell A, Yang S, Joksaite S, O'Reilly R, Van Dyke M, Albers FC, Kwon N. Effectiveness and safety of mepolizumab in real-world clinical practice: the REALITI-A study. Eur Resp J. 2019 54: OA2104.

34. Brusselle G, Germinaro M, Weiss S, Zangrilli J. Reslizumab in patients with inadequately controlled late-onset asthma and elevated blood eosinophils. Pulm Pharmacol Ther. 2017;43:39-45.

35. Castro M, Zangrilli J, Wechsler ME, Bateman ED, Brusselle GG, Bardin P, et al. Reslizumab for inadequately controlled asthma with elevated blood eosinophil counts: results from two multicentre, parallel, double-blind, randomised, placebo-controlled, phase 3 trials. Lancet Respir Med. 2015;3(5):355-66

36. Maselli DJ, Velez MI, Rogers L. Reslizumab in the management of poorly controlled asthma: the data so far. J Asthma Allergy. 2016;9:155-62

37. Nelson R, Bush A, Stokes J, Nair P, Akuthota P. Eosinophilic Asthma. J Allergy Clin Immunol Pract. 2020; 8(2):465-73.

38. Mukherjee M, Aleman P, Kjarsgaard M, Salter B, Nair G, LaVigne N, et al. Weight-adjusted Intravenous Reslizumab in severe asthma with inadequate response to fixed-dose subcutaneous mepolizumab. Am J Respir Crit Care Med. 2018;197(1):38-46.

39. Bleecker ER, FitzGerald JM, Chanez P, Papi A, Weinstein SF, Barker P, et al. Efficacy and safety of benralizumab for patients with severe asthma uncontrolled with high-dosage inhaled corticosteroids and long-acting beta2-agonists (SIROCCO): a randomised, multicentre, placebo-controlled phase 3 trial. Lancet. 2016;388(10056):2115-27.

40. FitzGerald JM, Bleecker ER, Nair P, Korn S, Ohta K, Lommatzsch M, et al. Benralizumab, an anti-interleukin-5 receptor alpha monoclonal antibody, as add-on treatment for patients with severe, uncontrolled, eosinophilic asthma (CALIMA): a randomised, double-blind, placebo-controlled phase 3 trial. Lancet. 2016;388(10056):2128-41.

41. Nair P, Wenzel S, Rabe KF, Bourdin A, Lugogo NL, Kuna P, et al. Oral Glucocorticoid-Sparing Effect of Benralizumab in Severe Asthma. N Engl J Med. 2017;376(25):2448-58.

42. Busse WW, Bleecker ER, FitzGerald JM, Ferguson GT, Barker P, Sproule S, et al. Long-term safety and efficacy of benralizumab in patients with severe, uncontrolled asthma: 1-year results from the BORA phase 3 extension trial. Lancet Respir Med. 2019;7(1):46-59.

43. Simpson EL, Bieber T, Guttman-Yassky E, Beck LA, Blauvelt A, Cork MJ et al. Two Phase 3 Trials of Dupilumab versus Placebo in Atopic Dermatitis. N Engl J Med. 2016;375(24):2335-48.

44. Blauvelt A, de Bruin-Weller M, Gooderham M, Cather JC, Weisman J, Pariser D, et al. Long-term management of moderate-to-severe atopic dermatitis with dupilumab and concomitant topical corticosteroids (LIBERTY AD CHRONOS): a 1-year, randomised, double-blinded, placebo-controlled, phase 3 trial. Lancet. 2017;389(10086):2287-303.

45. De Bruin-Weller M, Thaci D, Smith CH, Reich K, Cork MJ, Radin A, et al. Dupilumab with concomitant topical corticosteroid treatment in adults with atopic dermatitis with an inadequate response or intolerance to ciclosporin A or when this treatment is medically inadvisable: a placebo-controlled, randomized phase III clinical trial (LIBERTY AD CAFE). Br J Dermatol. 2018;178(5):1083-101.

46. Paller AS. Dupilumab for adolescents with Moderate-to-Severe Atopic Dermatitis: Results from a Phase 3, Randomized, Double-Blinded Trial. J Am Acad Dermatol. 2019;81(4):AB195

47. Worm M, Simpson EL, Thaçi D, Bissonette R, Lacour J-P, Beissert S, et al. Efficacy and safety of multiple dupilumab dose regimens after initial successful treatment in patients with atopic dermatitis. A Randomized Clinical Trial. JAMA Dermatol [Preprint]. 2019 [cited 2020 Jan 5]: [13 p]. Available from: https://jamanetwork.com/journals/jamadermatology/ fullarticle/2757721

48. Rabe KF, Nair P, Brusselle G, Maspero JF, Castro M, Sher L, et al. Efficacy and safety of dupilumab in glucocorticoid-dependent severe asthma. $\mathrm{N}$ Engl J Med. 2018;378(26):2475-85.

49. Castro M, Corren J, Pavord ID, Maspero J, Wenzel S, Rabe KF, et al. Dupilumab Efficacy and Safety in Moderate-to-Severe Uncontrolled Asthma. N Engl J Med. 2018;378(26):2486-96.

50. Corren J, Castro M, O’Riordan T, Hanania NA, Pavord ID, Quirce S, et al. Dupilumab efficacy in patients with uncontrolled, moderate-to-severe allergic asthma. J Allergy Clin Immunol Pract. 2020; 8(2):516-26 
51. Bachert C, Han JK, Desrosiers M, Hellings PW, Amin N, Lee SE, et al. Efficacy and safety of dupilumab in patients with severe chronic rhinosinusitis with nasal polyps (LIBERTY NP SINUS-24 and LIBERTY NP SINUS-52): results from two multicentre, randomised, double-blind, placebo-controlled, parallel-group phase 3 trials. Lancet. 2019;394(10209): 1638-50.

52. Wollenberg A, Howell MD, Guttman-Yassky E, Silverberg JI, Kell C, Ranade $\mathrm{K}$, et al. Treatment of atopic dermatitis with tralokinumab, an anti-IL-13 mAb. J Allergy Clin Immunol. 2019;143(1):135-41.

53. Simpson EL, Flohr C, Eichenfield LF, Bieber T, Sofen H, Taieb A, et al. Efficacy and safety of lebrikizumab (an anti-IL-13 monoclonal antibody) in adults with moderate-to-severe atopic dermatitis inadequately controlled by topical corticosteroids: A randomized, placebo-controlled phase II trial (TREBLE). J Am Acad of Dermatol. 2018;78(5):863-71 e11.

54. Corren J, Lemanske R, Hanania N, Korenblat P, Parsey M, Arron J, et al. Lebrikizumab Treatment in Adults with Asthma. N Engl J Med. 2011;365(12):1088-98.

55. Hanania N, Korenblat P, Chapman K, Bateman E, Kopecky P, Paggiaro $\mathrm{P}$, et al. Efficacy and safety of lebrikizumab in patients with uncontrolled asthma (LAVOLTA I and LAVOLTA II): replicate, phase 3, randomized, double-blind, placebo-controlled trials. Lancet Respir Med. 2016;4(10): 781-96.

56. Corren J, Parnes JR, Wang L, Mo M, Roseti SL, Griffiths JM, et al. Tezepelumab in Adults with Uncontrolled Asthma. N Engl J Med. 2017; 377(10):936-46.

57. Brunner PM, Pavel AB, Khattri S, Leonard A, Malik K, Rose S, et al. Baseline IL-22 expression in patients with atopic dermatitis stratifies tissue responses to fezakinumab. J Allergy Clin Immunol. 2019;143(1):142-54.

58. Lou H, Lu J, Choi EB, Oh MH, Jeong M, Barmettler S, et al. Expression of IL-22 in the skin causes Th2-biased immunity, epidermal barrier dysfunction and pruritus via stimulating epithelial Th2 Cytokines and the GRP Pathway. J Immunol. 2017;198(7):2543-55.

59. Guttman-Yassky E, Brunner PM, Neumann AU, Khattri S, Pavel AB, Malik $\mathrm{K}$, et al. Efficacy and safety of fezakinumab (an IL-22 monoclonal antibody) in adults with moderate-to-severe atopic dermatitis inadequately controlled by conventional treatments: A randomized, double-blind, phase $2 \mathrm{a}$ trial. J Am Acad Dermatol. 2018;78(5):872-81 e6.
60. Silverberg JI, Pinter A, Pulka G, Poulin Y, Bouaziz JD, Wollenberg A, et al. Phase $2 \mathrm{~B}$ randomized study of nemolizumab in adults with moderate-to-severe atopic dermatitis and severe pruritus. J Allergy Clin Immunol. 2020; 145(1): 173-82.

61. Toki S, Goleniewska K, Zhang J, Zhou W, Newcomb DC, Zhou B, et al. TSLP and IL-33 reciprocally promote each other's lung protein expression and ILC2 receptor expression to enhance innate type- 2 airway inflammation. Allergy [Preprint]. 2020 [cited 2020 Jan 5]: [28p.] Available from:.doi.org/10.1111/all.14196

62. Chinthrajah S, Cao S, Liu C, Lyu SC, Sindher SB, Long A, et al. Phase 2a randomized, placebo-controlled study of anti-IL-33 in peanut allergy. JCI Insight. 2019; 4(22):e 131347.

63. Busse W, Chupp G, Nagase H, Albers FC, Doyle S, Shen Q, et al. Anti-IL-5 treatments in patients with severe asthma by blood eosinophil thresholds: Indirect treatment comparison. J Allergy Clin Immunol. 2019;143(1): 190-200 e20.

64. Edris A, De Feyter S, Maes T, Joos G, Lahousse L. Monoclonal antibodies in type 2 asthma: a systematic review and network meta-analysis. Respir Res. 2019; 20(1):179.

65. Casale TB, Pacou M, Mesana L, Farge G, Sun SX, Castro M. Reslizumab Compared with Benralizumab in Patients with Eosinophilic Asthma: A Systematic Literature Review and Network Meta-Analysis. J Allergy Clin Immunol Pract. 2019;7(1):122-30 e1.

66. Nair P, Kjarsgaard M, Armstrong S, Efthimiadis A, O'Byrne P, Hargreave F. Nitric oxide in exhaled breath is poorly correlated to sputum eosinophils in patients with prednisone-dependent asthma. J Allergy Clin Immunol. 2010;126(2):404-6

67. Svenningsen S, Haider E, Eddy R, Parraga G, Nair P. Normalisation of MRI ventilation heterogenity in severe asthma by dupilumab. Thorax. 2019;74(11):1087-8.

68. Svenningsen S, Haider E, Boylan C, Mukherjee M, Eddy R, Capaldi D, et al. CT and Functional MRI to Evaluate Airway Mucus in Severe Asthma. Chest. 2019;155(6): 1178-89.

69. Svenningsen S, Nair P. Asthma endotypes and an over view of targeted therapy for asthma. Front Med. 2017; 4:158.

70. Gleich GJ, Klion AD, Lee JJ, Weller PF. The consequences of not having eosinophils. Allergy. 2013;68(7):829-35. 